Research Article

\title{
Traditional Childbearing Beliefs and Practices among Mothers at a District Hospital in Goa
}

\author{
Preksha P Vernekar', Jagadish A Cacodcar ${ }^{2}$, Minaxi Panandikar ${ }^{3}$, lra Almeida ${ }^{4}$ \\ ${ }^{1}$ Assistant Lecturer, ${ }^{2}$ Professor and Head, Department of Community Medicine, Goa Medical College, Goa, India. \\ ${ }^{3}$ Senior Gynaecologist, ${ }^{4}$ Senior Pediatrician, Directorate of Health Services, Goa, India. \\ DOI: https://doi.org/10.24321/2455.7048.202110
}

\section{I $\quad \mathbf{N} \quad \mathbf{F} \quad \mathbf{O}$}

\author{
Corresponding Author: \\ Preksha P Vernekar, Department of Community \\ Medicine, Goa Medical College, Goa, India. \\ E-mail Id: \\ preksha.vernekar23@gmail.com \\ Orcid Id: \\ https://orcid.org/0000-0001-6008-024X \\ How to cite this article: \\ Vernekar PP, Cacodar JA, Panandikar M, Almeida \\ I. Traditional Childbearing Beliefs and Practices \\ among Mothers at a District Hospital in Goa. \\ Epidem Int. 2021;6(3):27-33.
}

Date of Submission: 2021-08-28

Date of Acceptance: 2021-09-16

\section{$\begin{array}{llllllll}\mathbf{A} & \mathbf{B} & \mathbf{S} & \mathbf{T} & \mathbf{R} & \mathbf{A} & \mathbf{C} & \mathbf{T}\end{array}$}

Background: Traditional health practices are observed by mothers in every region of the world with varying frequency. They often get influenced by their peers and elders and follow some potentially harmful practices during their childbearing period.

Aim: To identify and describe various traditional beliefs and practices observed during pregnancy among mothers at South Goa District Hospital.

Methods: This is a descriptive, cross-sectional study. It was conducted over a period of 3 months (March-May 2019) among postnatal mothers by interviewing study participants about various cultural beliefs and practices observed during pregnancy. Data were entered into an Excel spreadsheet and analysed using SPSS version 22 .

Results: Nearly two-thirds of the study participants (68.75\%) avoided going outdoors and laid in bed during an eclipse while $42.5 \%$ avoided sleeping on the abdomen or slept in the left lateral position to avoid birth defects in babies. To predict the sex of the baby, $12.5 \%$ of the mothers believed that if a pregnant lady craves sweet food, it's a girl and if she craves sour/ salty food, it's a boy while $11.5 \%$ believed that if a pregnant woman is carrying low, it's a boy. With respect to food taboos, 53.75\% of the mothers believed in avoiding 'hot' foods and eating 'cold' foods during pregnancy.

Conclusion: The study highlights the popular traditional childbearing practices observed among mothers as a means of creating awareness among health professionals in order to discourage possible harmful practices and promote beneficial practices for a safe and healthy pregnancy.

Keywords: Tradition, Cultural Practices, Pregnancy, Infant, Maternal Health

\section{Introduction}

Pregnancy is a normal biological phenomenon significantly influenced by religious and traditional practices and beliefs in the Indian context. These traditions reflect community beliefs regarding what is helpful for the pregnant woman and her unborn baby. ${ }^{1}$ Pregnant women exhibit their faith 
in these beliefs and practices to ensure the protection of pregnancy and safe delivery. However, cultural beliefs, improper religious practices, and several Indian norms may directly or indirectly affect the health status of pregnant women in varying severity. The antenatal period in itself poses health challenges to women and a different outlook towards life as it leads to drastic alterations such as physiological and physical changes, emotional stress, mood swings, lack of self-care and missed periods.

Maternal health is one of the predominant keystones for the progress of any nation. It helps in the development of its citizens, reduction of poverty, and in building social capital. Reduction in maternal mortality is one of the principal indicators of the Sustainable Development Goals. ${ }^{2}$ A healthy and uncomplicated pregnancy can be achieved by ensuring frequent antenatal check-ups and safe institutional deliveries. Reduction in maternal and child mortality ratio can be achieved by ensuring the fulfilment of these criteria.

Cultural beliefs predominant in Indian societies can largely affect the utilisation of maternal health care services. Moreover, misinterpretation, insensitivity and lack of impressionability towards cultural perceptions of the society dictating pregnancy among health care providers may lead to a break in the channel of communication with the pregnant woman and her family. ${ }^{3} \mathrm{~A}$ pregnant woman's fear of redundant medical interventions can also lead to possible problems or risks going undiagnosed for a long time during pregnancy, which will further delay the woman from seeking institutional care. These demand-side barriers favour the rampage of familiar practitioners in the community providing informal health care. ${ }^{4}$

Considering the fact that there is limited data in Goa on traditional beliefs and cultural practices observed during the antenatal period, the present study was undertaken among postnatal mothers admitted at South Goa District Hospital to shed light on this topic to implement effective strategies for ensuring safe motherhood among pregnant women and to promote cultural competence among health professionals towards antenatal care.

\section{Materials and Methods}

This observational descriptive study was conducted over a period of 3 months (March-May 2019) among mothers within 72 hours of postnatal period admitted in the respective wards of the South Goa District Hospital, Margao. During the study period, data were collected thrice weekly from 80 study participants who were interviewed face to face using a pre-designed, pre-tested, semi-structured questionnaire after explaining the rationale of the study to them and obtaining written informed consent.

The questionnaire used for obtaining data from the study participants comprised of questions concerning socio- demographic data of the study participants like age, sex, religion, occupation, education, etc, cultural beliefs and practices observed during pregnancy, and forbidden practices and food taboos during pregnancy.

Before beginning the study, the required ethical approval was obtained from the Institutional Ethics Committee (IEC) of Goa Medical College.

Data were entered into a Microsoft Excel spreadsheet and analysed using SPSS version 22. Descriptive statistics were used to present the data.

\section{Results}

The socio-demographic data of the study participants showed that majority of the mothers were aged between 19 and 25 years. Majority of the mothers were Goans (61.25\%). Of the total, $22.5 \%$ of the mothers interviewed had completed lower primary school education. A considerable proportion of the study participants were not employed (93.75\%). As per modified B. G. Prasad Classification, Update - 2019, $41.25 \%$ of the mothers belonged to Class III socioeconomic status. The additional details regarding socio-demographic profile of the study participants have been mentioned in a previously published study. ${ }^{5}$

Table 1 describes some of the traditional beliefs observed by mothers to avoid birth defects in babies during pregnancy. Nearly two-thirds of the study participants (68.75\%) avoided going outdoors and laid in bed during an eclipse while $42.5 \%$ avoided sleeping on the abdomen and slept in the left lateral position. Other such practices observed were limiting physical activity (32.5\%), avoiding flights (22.5\%), and avoiding lift/ escalator (15\%).

Table I.Traditional Beliefs among Mothers to Avoid Birth Defects in Babies during Pregnancy

\begin{tabular}{|c|c|}
\hline \multicolumn{1}{|c}{ Beliefs } & Number (\%) \\
\hline $\begin{array}{c}\text { Avoid going outdoors and lay in bed } \\
\text { during an eclipse }\end{array}$ & $55(68.75)$ \\
\hline $\begin{array}{c}\text { Avoid sleeping on stomach/ sleeping in } \\
\text { left lateral position }\end{array}$ & $34(42.5)$ \\
\hline Limit physical activity & $26(32.5)$ \\
\hline Avoid flights/ travelling & $18(22.5)$ \\
\hline Avoid lift/ escalator & $12(15.0)$ \\
\hline
\end{tabular}

As far as the prediction of the sex of baby during pregnancy is concerned, $12.5 \%$ of the mothers believed that if a pregnant lady craves sweet food, it's a girl, and it's a boy if she craves sour/ salty food while $11.25 \%$ believed that if a pregnant woman is carrying low, it's a boy. Furthermore, the size of womb during the third trimester of pregnancy was believed to predict a baby's sex by $5 \%$ of the mothers. 
$3.75 \%$ of the mothers believed that the facial appearance of a pregnant lady can predict the baby's sex (Table 2).

Table 2.Traditional Beliefs among Mothers to Predict the Sex of Baby during Pregnancy

\begin{tabular}{|c|c|}
\hline Beliefs & Number (\%) \\
\hline $\begin{array}{l}\text { If a pregnant woman craves sweet food, } \\
\text { it's a girl, and if she craves sour/ salty } \\
\text { food, it's a boy }\end{array}$ & $10(12.5)$ \\
\hline $\begin{array}{l}\text { If a pregnant woman is carrying low, it's } \\
\text { a boy }\end{array}$ & $9(11.25)$ \\
\hline Size of the womb & $4(5.0)$ \\
\hline $\begin{array}{l}\text { If a pregnant woman has a glowing face, } \\
\text { it's a girl }\end{array}$ & $3(3.75)$ \\
\hline Position of the umbilicus & $2(2.5)$ \\
\hline $\begin{array}{c}\text { Excessive morning sickness indicates it's } \\
\text { a girl }\end{array}$ & $2(2.5)$ \\
\hline If you have acne while pregnant, it's a girl & $1(1.25)$ \\
\hline $\begin{array}{l}\text { If you see a parrot in your dreams, it's } \\
\text { a boy }\end{array}$ & $1(1.25)$ \\
\hline
\end{tabular}

Among the 80 study participants, it was observed that some practices were forbidden during pregnancy to ensure the well-being of mother and baby. Almost half of the mothers, i.e., $47.5 \%$ were advised to avoid attending funerals while $40 \%$ were prohibited from worshipping God or performing rituals at religious ceremonies. Other practices found to be noteworthy were to avoid talking to widows or women with infertility issues (35\%), to avoid cooking food during festivals $(20 \%)$, and to avoid wearing new clothes $(7.5 \%)$ (Table 3).

Table 3.Forbidden Practices among Mothers during Pregnancy

\begin{tabular}{|c|c|}
\hline Practices & Number (\%) \\
\hline Attending funerals & $38(47.5)$ \\
\hline Worshipping God/ performing rituals & $32(40.0)$ \\
\hline $\begin{array}{c}\text { Avoid seeing/ talking to widows/ } \\
\text { infertile women }\end{array}$ & $28(35.0)$ \\
\hline Cooking food during festivals & $16(20.0)$ \\
\hline Wearing new clothes & $6(7.5)$ \\
\hline
\end{tabular}

While some practices were forbidden during pregnancy, certain other additional traditional beliefs and practices were assessed among the study participants. It was noted that $48.75 \%$ of the mothers had observed a baby shower at the 5th or 7th month of pregnancy to celebrate the anticipated arrival of their first child. A significant proportion of mothers (63.75\%) were advised to stay at their maiden home during the third trimester of pregnancy. When the mothers were asked about sexual intercourse during pregnancy, majority of the mothers $(52.5 \%)$ couldn't comment on the safety of sexual activity while being pregnant. In addition, 53.75\% of the mothers believed in avoiding 'hot' foods and eating 'cold' foods during pregnancy (Table 4).

Table 4.Selected Traditional Practices observed among Mothers during Pregnancy

$(\mathrm{N}=80)$

\begin{tabular}{|c|c|}
\hline Practices & Number (\%) \\
\hline $\begin{array}{l}\text { Observing baby shower at } 5 \text { th } / 7 \text { th } \\
\text { month of pregnancy before the arrival } \\
\text { of first child }\end{array}$ & $39(48.75)$ \\
\hline $\begin{array}{l}\text { Staying at maiden home during late } \\
\text { pregnancy }\end{array}$ & $51(63.75)$ \\
\hline \multicolumn{2}{|l|}{ Sexual intercourse during pregnancy } \\
\hline Yes & $12(15.0)$ \\
\hline No & $26(32.5)$ \\
\hline Don't know & $42(52.5)$ \\
\hline \multicolumn{2}{|c|}{$\begin{array}{l}\text { Avoiding hot foods and eating cold foods during } \\
\text { pregnancy }\end{array}$} \\
\hline Yes & $43(53.75)$ \\
\hline No & $15(18.75)$ \\
\hline Don't know & $22(27.5)$ \\
\hline
\end{tabular}

Table 5.Food Items Consumed by Mothers during Pregnancy with Reasons

\begin{tabular}{|c|c|}
\hline Food Items & Reason for Consumption \\
\hline $\begin{array}{c}\text { Fruits (apple, banana), } \\
\text { green leafy vegetables, } \\
\text { milk, egg, curds, cooked dal }\end{array}$ & $\begin{array}{c}\text { To improve the well- } \\
\text { being of mother and } \\
\text { baby }\end{array}$ \\
\hline $\begin{array}{c}\text { Almonds, pistachios, dry } \\
\text { grapes }\end{array}$ & $\begin{array}{c}\text { To increase IQ of the } \\
\text { baby }\end{array}$ \\
\hline $\begin{array}{c}\text { Rawa, ragi, fenugreek bhaji, } \\
\text { jowar roti }\end{array}$ & $\begin{array}{c}\text { To increase milk } \\
\text { production }\end{array}$ \\
\hline $\begin{array}{c}\text { Saffron powder (in milk or } \\
\text { water) }\end{array}$ & $\begin{array}{c}\text { For fairer complexion of } \\
\text { the baby }\end{array}$ \\
\hline Protein supplements & $\begin{array}{c}\text { For increased energy to } \\
\text { support pregnancy }\end{array}$ \\
\hline
\end{tabular}

With respect to food taboos, food such as some fruits (apple, banana), green leafy vegetables, milk, egg, curds, and cooked dal were preferred to improve maternal and foetal health. Dry fruits such as almonds, pistachios, and dry grapes were consumed to increase the Intelligence Quotient (IQ) of the baby. Interestingly, foods such as rawa, ragi, fenugreek bhaji and jowar roti were advised by elders for efficient lactation (Table 5). However, certain foods 
were believed to cause harm to the mother or the growing foetus. Selected fruits such as papaya, pineapple, jackfruit, watermelon, mango, and pumpkin were believed to act as abortifacients while grapes and oranges were believed to cause common cold in mothers. Interestingly, fused bananas were not eaten to avoid twin pregnancy (Table 6).

Table 6.Food Items Avoided by Mothers during Pregnancy with Reasons

$(\mathrm{N}=80)$

\begin{tabular}{|c|c|}
\hline Food Items & Reason for Avoidance \\
\hline $\begin{array}{c}\text { Fruits (papaya, pineapple, } \\
\text { jackfruit, watermelon, } \\
\text { mango, pumpkin) }\end{array}$ & Act as abortifacients \\
\hline Fruits (grapes, orange) & Can cause cough and cold \\
\hline Fused fruits (banana) & Can cause twin pregnancy \\
\hline Shellfish & $\begin{array}{c}\text { Induce pre-labour } \\
\text { contractions }\end{array}$ \\
\hline Potatoes, pulses, oil, ghee & $\begin{array}{c}\text { Cause an abdominal } \\
\text { bloating sensation }\end{array}$ \\
\hline Brinjal & Causes indigestion \\
\hline Spices & $\begin{array}{c}\text { Can cause damage to } \\
\text { baby's eyes }\end{array}$ \\
\hline Meat (chicken, mutton), \\
chocolates & $\begin{array}{c}\text { Increase production of } \\
\text { heat in the body }\end{array}$ \\
\hline
\end{tabular}

\section{Discussion}

The present study highlights a number of traditional beliefs and practices particularly aiming to ensure the safety of mother and baby during the antenatal period. These customs have no scientific evidence and are usually prejudices that have become part of social culture. Previously published literature suggests that women observed these customs to respect traditions, or because of family pressure or pressure from elders, even when they did not consider them to be important or believe in practising them. This was because they had their apprehensions about the possible negative consequences (to the growing foetus and the mother) in case they chose not to adhere to these customs. ${ }^{6}$

Although maternal practices are being modified to ensure their suitability to the present context of modern women's lives, yet our review shows that many conventional practices are still being followed in various Asian cultures. ${ }^{7}$ It has also been observed that most of such beliefs do not pose any harm or have any adverse impact on women or their babies. As a matter of fact, many among them actually help the women physically and psychologically, such as birth position and confinement practices. Hence it is important for healthcare providers to comprehend these prevalent practices while promoting and providing care to enhance utilisation and boost service-user's satisfaction.
In the present study, it was observed that the study participants took certain precautions to prevent birth defects in the growing foetus, miscarriage, or stillbirth during pregnancy. A large majority of the study participants were advised to avoid going outdoors and lay still in bed during an eclipse (68.75\%). Nayak et al. (2020), in a similar study, observed that $40.7 \%$ of pregnant women believe in not eating food or cutting anything during an eclipse. ${ }^{8}$ As per astrological opinions, pregnant women should be extra cautious at the time of an eclipse. The expecting mother should not step out of their homes as it can lead to premature labour or structural abnormalities. Some cultures suggest that they should not eat, drink or even sleep during this time. ${ }^{9}$ Other practices include avoiding lying on one's abdomen or sleeping in left lateral position (42.50\%), limiting physical work (32.5\%), and avoiding flights $(22.5 \%)$ which were consistent with findings from a study done by lyengar et al. ${ }^{10}$ wherein activities such as farm work involving lifting heavy objects (i.e. rice bag or water buckets), driving, lying on one's abdomen, and even bathing during the first month after childbirth were avoided to prevent miscarriage or stillbirth.

Studies have shown that the gender of the child can be predicted by the physical appearance of pregnant woman, the foods she craves, and her behaviour at times. In our study, $12.5 \%$ of the study participants indicated that if the pregnant lady craves sweet food, it's a girl, and if she craves sour/ salty food, it's a boy, while $11.25 \%$ believed that if the pregnant woman is carrying low, it's a boy. In addition, $5 \%$ noted that an enlarged belly signified a boy while a small belly would be carrying a girl. The glowing face of a woman during pregnancy predicted the child to be a girl in $3.75 \%$ of the mothers. An everted umbilicus predicted a boy while an inverted umbilicus predicted a girl in $2.5 \%$ of the mothers. These findings were congruent with a study done by Karahan et al. in Istanbul, Turkey. ${ }^{11}$ Okka et al. ${ }^{12}$ in their study also noted that the baby's sex could be predicted from the shape of mother's abdominal region $(32.4 \%)$ and from the changes on mother's face (27.1\%). Literature published in the past tends to highlight the beliefs surrounding prediction of the gender of a baby and the views thought to be related to the gender roles attributed to men and women in the society. The assumed traditional gender roles in our society expect women to be passive and calm, while men are supposed to be strong, resilient, assertive, and independent. A significant proportion of women are disadvantaged in the patriarchal societies of India. Male-child preference is deeply rooted, especially in Hinduism, to continue the family line and perform funeral rites. $^{13}$

Various taboos have been found to be linked to certain astrological beliefs of people regarding the dangers that pregnant women and their foetuses may have to face. In 
the present study, a significant proportion of the study participants were forbidden from attending funerals (47.5\%) which was similar to the findings of a study done by Nayak et al. ${ }^{8}$ wherein $51 \%$ strongly agreed with the belief of avoiding funerals during pregnancy to prevent miscarriage or stillbirth and to ward off the wrath of evil spirits on the unborn baby. In addition, $40 \%$ were not allowed to worship God or perform any rituals, particularly among Hindus. Another 35\% weren't allowed to interact with widows or infertile women which correlated with the findings of a survey by students of DCH Nsg ${ }^{14}$ while $20 \%$ weren't allowed to cook food for offering to God during festivals. While there is no scientific evidence to suggest the ill-effects of these practices, it is believed that pregnant women are considered impure, hence, they should refrain from touching food or water sources and avoid pious and pure places such as temples and kitchens as seen by Legare et al. in Bihar. ${ }^{15}$

In our study, it was observed that $48.75 \%$ of the study respondents reported observing a baby shower during pregnancy before the arrival of the first child. In a study conducted by Choudhary et al. in North India, a similar ceremony called 'Godh Bharai' was observed by $53 \%$ of the study population. ${ }^{16}$ Another study done in West Bengal observed the celebration of a similar ceremony called 'Saddah'. In Goa, this ceremony is popularly called 'fulam malop' (adorn the coiffure with flowers) and is observed by Hindus to celebrate the arrival of the first child. ${ }^{17}$ It is held either in the 5th, 7th, or 9th month of pregnancy before the expectant mother is sent to her maiden home for confinement. The expecting mother is decked up in flower jewellery and costumed in a traditional saree to symbolise the Hindu Goddess Lakshmi or Saraswati and is showered with gifts by her family and well-wishers. ${ }^{18}$ The ladies put tikka (vermilion) on the mother's forehead and whisper advice about motherhood into her ears; everyone then prays for her and the baby's wellbeing. A similar custom is observed among Muslims wherein parents visit their expecting daughter's home in the 7th month of pregnancy with lots of sweets, food, and new clothes for their daughter and son in law. ${ }^{19}$

In our study, $63.75 \%$ of the mothers were advised to stay at their maiden house during the third trimester of pregnancy. Choudhary et al. ${ }^{16}$ also observed a comparable proportion of $18 \%$ of mothers planning to stay with their own mother after delivery. In Goa, it is known that mothers are advised to go to their maiden home called 'kular' in Konkani during the third trimester of pregnancy and postpartum for confinement. ${ }^{17}$

In the present study, when the mothers were asked about their views on sexual intercourse while being pregnant, $52.5 \%$ of the respondents couldn't comment on the safety of sexual activity during pregnancy, irrespective of their choices. Only $15 \%$ believed that sex is safe while $32.5 \%$ did not consider it safe. It was found that they generally avoided coitus from their 3-8 months of pregnancy to at least 3 months postpartum. Morris et al. ${ }^{20}$ noted among their participants in southeast Madagascar that it is believed that the partner of a pregnant woman should not have sex with casual partners during her pregnancy because it might have an adverse effect on the unborn baby. Beinempaka et al. found that sexual activity is not permitted for one month after delivery among pregnant women. ${ }^{21}$

The general concept around food taboos during pregnancy is that acidic, high protein, and salty foods are believed to be 'hot', and fruits, vegetables, and sweet foods are believed to be 'cold'. There is no definite correlation between the 'hot' and 'cold' concept of food and its temperature. Pregnancy is considered to be a 'hot' state and cold foods are preferred, but in certain places, especially in India, it is also opined that hot food helps with the onset of delivery and hence is advised towards the end of pregnancy. ${ }^{1}$ Pregnancy, itself, is believed to be an over-heated state, and the physiological changes that occur during pregnancy may cause a hot/ cold imbalance in the body. Hence, cold foods are believed to keep this balance in check to counteract the "overheated" state of pregnancy. ${ }^{22}$ These views were supported by $53.75 \%$ of the respondents in our study as also in various studies conducted in India and abroad. Begum et al..$^{23}$ in a similar study among tribal women of Maharashtra revealed that pregnant women of Korgu tribe denied eating "hot" foods such as papaya, banana, shevaga, til, and masur dal. Gedamu et al. in their study observed that the prevalence of nutritional taboos was $19.5 \% .^{24}$

Selective fruits (apple, banana) and green leafy vegetables, milk, egg, curds, and cooked dal were the most commonly mentioned beneficial food items to improve the well-being of mothers during pregnancy. These results were consistent with the qualitative findings of Catherin et al. wherein fruits like apple, lemon, meat like chicken, mutton, egg, and groundnut powder were believed to improve maternal and child health, however, the intake of egg and fish were thought to cause ear discharge and hair loss in babies. ${ }^{25}$ Intake of dry fruits such as almonds and pistachios was thought to improve IQ of babies as seen in $0.2 \%$ of mothers in a study by Karahan et al. ${ }^{11}$ Foods consumed for increased lactation were semolina porridge (rawa), ragi (satva/ tizaan), fenugreek (methi) bhaji, and jowar roti (zonle bhakri).

In our study, the study participants were advised to avoid fruits such as papaya, pineapple, jackfruit, watermelon, mango, and pumpkin as they were believed to act as abortifacients. These views correlated with the findings of Nayak et al. ${ }^{8}$ wherein intake of pineapple was strictly avoided by $41.5 \%$ of pregnant mothers. It is believed that foods such as ripe papaya and pineapple are considered to 
be purgative in action or could cause abdominal pain and uterine contractions ultimately leading to miscarriage..$^{26,27}$ Some thought-provoking beliefs such as fruits like grapes or orange cause common cold or foods such as potatoes, oil or ghee cause abdominal bloating and discomfort, could hint at excess intake of these foods. However, other beliefs stated for some food items such as spices causing damage to baby's eyes or fused bananas causing twin pregnancy can be correlated with that of the study by Catherin et al. ${ }^{25}$ and had no scientific explanation. The traditional beliefs surrounding diet during pregnancy emphasise the importance of educating women, especially regarding nutrition, in order to change their attitude towards balanced feeding habits to prevent lack of adequate nourishment among pregnant and lactating women which may, in turn, affect the growth of the baby.

\section{Conclusion}

The present study highlights the various cultural beliefs and practices observed during pregnancy in Goa. It is desired that health professionals should be aware of these cultural practices followed by the community to provide culturally competent health care that is acceptable to society. It is recommended that harmless, acceptable or even potentially beneficial practices observed during the antenatal period may be supported and considered a part of our rich culture, whereas harmful beliefs and practices should be avoided along with debunking ritualistic myths which threaten the physical and mental well-being of a pregnant woman by providing nutrition and health education during antenatal visits to avoid potential adverse health effects among these mothers.

\section{Limitations}

Our study can be viewed as a pilot project for the assessment of traditional practices observed during pregnancy among postnatal mothers. It is recommended to conduct a largescale epidemiological study preferably with a mixed-method model to procure further information. The limitation of this study was that the respondents might be subjected to recall bias. It is desirable to draw comparisons among cultural beliefs across religions or regions (rural or urban).

\section{Source of Funding: None \\ Conflict of Interest: None}

\section{References}

1. Wells YO, Dietsch E. Childbearing traditions of Indian women at home and abroad: an integrative literature review. Women Birth. 2014 Dec;27(4):e1-6. [PubMed] [Google Scholar]

2. Grove J, Claeson M, Bryce J, Amouzou A, Boerma T, Waiswa P, Victora C; Kirkland Group. Maternal, newborn, and child health and the Sustainable
Development Goals-a call for sustained and improved measurement. Lancet. 2015 Oct;386(10003):1511-4. [PubMed] [Google Scholar]

3. Morton A. Traditional practices and adverse pregnancy outcomes in migrant women. Obstet Med. 2017 Mar;10(1):45-6. [PubMed] [Google Scholar]

4. Cetin H, Gunay N, Dalak H. Traditional practices to women during pregnancy, birth and after birth and reasons. Healthmed. 2012;6(7):2396-406. [Google Scholar]

5. Vernekar PP, Cacodcar JA, Panandikar M, Almeida I. A study on traditional beliefs and practices during the postpartum period among mothers at a district hospital in Goa. Int J Preven Curat Comm Med. 2021;7(3):1-11. [Google Scholar]

6. Ahmad N, Syed Nor SF, Daud F. Understanding myths in pregnancy and childbirth and the potential adverse consequences: a systematic review. Malays J Med Sci. 2019;26(4):17-27. [PubMed] [Google Scholar]

7. Sultana Z, Chowdhury L, Shapla NR. Study on superstitions related to pregnancy. J Natl Inst Neurosci Bangladesh. 2019 Sep 7;5(2):172-6. [Google Scholar]

8. Nayak D, Dey S. Cultural beliefs on antenatal care among women in selected areas of Bhubaneswar - a descriptive study. Eur J Mol Clin Med. 2020;7(11):502737. [Google Scholar]

9. Times of India [Internet]. Solar eclipse: the effect of surya grahan on pregnant women; 2020 [cited 2021 Sep 20]. Available from: https://timesofindia. indiatimes.com/life-style/parenting/moments/solareclipse-pregnancy-precautions-the-effect-of-suryagrahan-on-pregnant-women-solar-eclipse-effects-onpregnancy-surya-grahan-precautions-for-pregnantladies/articleshow/79704500.cms

10. lyengar SD, lyengar K, Martines JC, Dashora K, Deora KK. Childbirth practices in rural Rajasthan, India: implications for neonatal health and survival. J Perinatol. 2008 Dec;28(S2):S23-30. [PubMed] [Google Scholar]

11. Karahan N, Aydın R, Güven DY, Benli AR, Kalkan NB. Traditional health practices concerning pregnancy, birth, and the postpartum period of women giving birth in the hospital. South Clin Ist Euras. 2017;28(3):190-8. [Google Scholar]

12. Okka B, Durduran Y, Kodaz ND. Traditional practices of Konya women during pregnancy, birth, the postpartum period, and newborn care. Turk J Med Sci. 2016;46:50111. [PubMed] [Google Scholar]

13. Sarkar S. Pregnancy, birthing, breastfeeding and mothering: hindu perspectives from scriptures and practices. Open Theology. 2020;6:104-16. [Google Scholar]

14. Nsg DC. Beliefs and practices of antenatal mothers in a rural setting. Nurs J India. 1995 Jan;86(1):4-6. [PubMed] [Google Scholar] 
15. Legare $\mathrm{CH}$, Akhauri $\mathrm{S}$, Chaudhuri I, Hashmi FA, Johnson T, Little EE, Lunkenheimer HG, Mandelbaum A, Mandlik H, Mondal S, Mor N, Saldanha N, Schooley J, Sharda P, Subbiah S, Swarup S, Tikkanen M, Burger O. Perinatal risk and the cultural ecology of health in Bihar, India. Philos Trans R Soc Lond B Biol Sci. 2020 Aug 17;375(1805):20190433. [PubMed] [Google Scholar]

16. Choudhary R, Gothwal S, Nayan S, Meena BS. Common ritualistic myths during pregnancy in Northern India. Int J Contemp Pediatr. 2017;4(5):1644-7. [Google Scholar]

17. Webindia123 [Internet]. Religious practices Sacraments among hindus; 2021 [cited 2021 Sep 19]. Available from: https://www.webindia123.com/goa/ people/sacraments.htm

18. Das A. Of flowers and fertility [Internet]. The Times of India; 2017 [cited 2021 Sep 22]. Available from: https:// timesofindia.indiatimes.com/city/goa/of-flowers-andfertility/articleshow/58771325.cms

19. Webindia123 [Internet]. Religious practices Sacraments among muslims; 2021 [cited 2021 Sep 19]. Available from: https://www.webindia123.com/ goa/people/muslim.htm

20. Morris JL, Short S, Robson L, Andriatsihosena MS. Maternal health practices, beliefs and traditions in southeast Madagascar. Afr J Reprod Health. 2014;18(3):101-17. [PubMed] [Google Scholar]

21. Beinempaka F, Tibanyendera B, Atwine F, Kyomuhangi T, Kabakyenga J, MacDonald NE. Traditional rituals and customs for pregnant women in selected villages in southwest Uganda. J Obstet Gynaecol Can. 2015 Oct;37(10):899-900. [PubMed] [Google Scholar]

22. Withers M, Kharazmi N, Lim E. Traditional beliefs and practices in pregnancy, childbirth and postpartum: a review of the evidence from Asian countries. Midwifery. 2018 Jan;56:158-70. [PubMed] [Google Scholar]

23. Begum S, Sebastian A, Kulkarni R, Singh S, Donta B. Traditional practices during pregnancy and childbirth among tribal women from Maharashtra: a review. Int J Community Med Public Health. 2017 Mar 28;4(4):882. [Google Scholar]

24. Gedamu H, Tsegaw A, Debebe E. The prevalence of traditional malpractice during pregnancy, child birth, and postnatal period among women of childbearing age in Meshenti Town, 2016. Int J Reprod Med. 2018;2018: 5945060. [PubMed] [Google Scholar]

25. Catherin N, Rock B, Roger V, Ankita C, Ashish G, Delwin $P$, Shanbhag D, Goud BR. Beliefs and practices regarding nutrition during pregnancy and lactation in a rural area in Karnataka, India: a qualitative study. Int J Community Med Public Health. 2015;2(2):116-20. [Google Scholar]

26. Saxena V, Jelly P, Sharma R. An exploratory study on traditional practices of families during the perinatal period among traditional birth attendants in
Uttarakhand. J Family Med Prim Care. 2020;9(1):15661. [PubMed] [Google Scholar]

27. Banu KK, Prathipa A, Anandarajan B, Ismail Sheriff AM, Muthukumar S, Selvakumar J. Food taboos during antenatal and postpartum period among the women of rural and urban areas of Tamilnadu. Int J Biomed Adv Res. 2016 Aug 30;7(8):393-6. [Google Scholar] 